\title{
Le Verrier
}

\section{Savant magnifique et détesté}

\author{
James Lequeux
}

Astronome à l'Observatoire de Paris

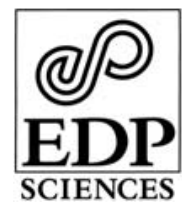

17, avenue du Hoggar

Parc d'Activité de Courtabœuf, BP 112 91944 Les Ulis Cedex A, France

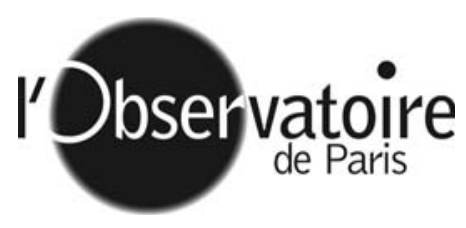

61, avenue de l'Observatoire 75014 Paris

France 
Imprimé en France

Illustration de couverture : Le Verrier découvre la planète Neptune, par Edmond Levis Dupain (1889) : fragment.

Crédit : Observatoire de Paris.

ISBN EDP Sciences : 978-2-7598-0422-1

ISBN Observatoire de Paris : 978-2-901057-61-1

Tous droits de traduction, d'adaptation et de reproduction par tous procédés, réservés pour tous pays. La loi du 11 mars 1957 n'autorisant, aux termes des alinéas 2 et 3 de l'article 41, d'une part, que les « copies ou reproductions strictement réservées à l'usage privé du copiste et non destinées à une utilisation collective », et d'autre part, que les analyses et les courtes citations dans un but d'exemple et d'illustration, " toute représentation intégrale, ou partielle, faite sans le consentement de l'auteur ou de ses ayants droit ou ayants cause est illicite » (alinéa $1^{\text {er }}$ de l'article 40). Cette représentation ou reproduction, par quelque procédé que ce soit, constituerait donc une contrefaçon sanctionnée par les articles 425 et suivants du code pénal.

(C) 2009 EDP Sciences 